\title{
Management of obesity in adolescents: state of art
}

\author{
Controle da obesidade em adolescentes: atualização
}

Amélio F. De Godoy-Matos ${ }^{1}$, Erika Paniago Guedes ${ }^{1}$, Luciana Lopes de Souza', Mariana Farage Martins'

'Serviço de Metabologia do Instituto Estadual de Diabetes e Endocrinologia (IEDE), Rio de Janeiro, RJ, Brasil

Correspondence to: Amélio F. De Godoy-Matos Rua Moncorvo Filho, 90, Serviço de Metabologia do Instituto Estadual de Diabetes e Endocrinologia (IEDE/RJ), Centro

20211-340 - Rio de Janeiro, RJ, Brasil

godoymatos@openlink.com.br

\begin{abstract}
Increasing prevalence of obesity in children and adolescents might represent an emerging public health issue. Pathogenesis of obesity is multifactorial and involves a complex interplay of genetic and environmental factors. Adolescent obesity has been seen as a cosmetic problem only; nevertheless, a significant increase in cardiovascular risk, probably due to obesity-related metabolic disarrangement has been observed. Consequently, discussion on strategies for treating childhood and adolescent obesity has been promoted worldwide. The proposed treatment triad is life style modification, pharmacological, and surgical treatment. Although lacking definitive data, drug therapy has emerged as an efficacious tool, at least in adolescent obesity. Therefore, sibutramine and orlistat may be good therapeutic options when life style modifications alone do not work. Arq Bras Endocrinol Metab. 2009;53(2):252-261.
\end{abstract}

Keywords

Obesity; adolescent; anti-obesity agents; treatment; sibutramine; metformin; orlistat; bariatric surgery

\section{RESUMO}

O aumento da prevalência de obesidade em crianças e adolescentes pode representar um sério problema de saúde pública nos próximos anos. A patogênese da obesidade é multifatorial e envolve uma complexa interação de fatores genéticos com fatores ambientais. A obesidade na adolescência tem sido vista apenas como um problema estético, entretanto, tem sido observado significativo aumento de fatores de risco cardiovasculares, provavelmente em razão das alterações metabólicas relacionadas ao excesso de peso. Desde então, estratégias de tratamento da obesidade na infância e adolescência têm sido propostas. $O$ tripé proposto para o tratamento é: mudança de estilo de vida, tratamento medicamentoso e cirúrgico. Apesar da falta de evidências definitivas, o tratamento medicamentoso em adolescentes emerge como uma ferramenta eficaz. Sibutramina e orlistat, desse modo, podem ser uma boa opção terapêutica quando as mudanças de estilo de vida, isoladamente, não forem eficazes. Arq Bras Endocrinol Metab. 2009;53(2):252-261.

Received in Jan/30/2009

Accepted in Feb/15/2009

Descritores

Obesidade; adolescentes; agentes antiobesidade; orlistat; sibutramina; metformina; cirurgia bariátrica

\section{INTRODUCTION}

$\mathrm{T}$ he prevalence of obesity in children and adolescents has increased dramatically in the past three decades, not only in the developed countries, but also in the least developed ones. Based on the heights and weights measured from nationally representative samples of US children, that have been assessed approximately every 5 years, obesity prevalence has increased from 5\% in 1963 to 1970 to $17 \%$ in 2003 to 2004 (1).

Increasing incidence of childhood obesity, mostly in least developed countries, might represent a potential emerging public health issue, which in turn is likely to create an enormous socioeconomic and public health burden in the near future (2). Brazil has registered an increase in obesity in the pediatric population from $4.1 \%$ to $13.9 \%$, between 1974 and 1997 , with an estimated $16.7 \%$ obese adolescents in 2002-2003 $(3,4)$.

The pathogenesis of obesity is multifactorial and involves a complex interplay of genetic (metabolic and hormonal) and environmental (lifestyle, behavior, and socioeconomic) factors (2). Twin studies have clearly demonstrated a "genetic risk factor", as obese parents 
are more likely to have obese children. The discovery of leptin, ghrelin, adiponectin, and other hormones that influence appetite, satiety, and fat distribution provides insight into metabolic mechanisms that represent the physiologic risk. Multiple substances and multiple gene sites have been associated with obesity making a complex system that must not respond to a simple therapeutic intervention. Moreover, as far as the population aspect is concerned, the increase in prevalence is too rapid to be explained only by a genetic shift (5). The main cause of obesity in children is due to exogenous (environmental) factors. The epidemic of obesity is due to a gradually increasing caloric intake and decreasing physical activity. A positive energy balance (energy from food intake greater than energy expenditure in daily activities and exercise) of only 50 to $100 \mathrm{kcal}$ per day can lead to a $2.0 \mathrm{~kg}$ to $5.0 \mathrm{~kg}$ weight gain over a 1 -year period. Less than $1 \%$ of childhood obesity in tertiary care centers is caused by endocrine and genetic diseases (6). Secondary causes of obesity are even less observed (Table 1) (6).

\begin{tabular}{l}
\hline Table 1. Secondary causes of obesity \\
\hline Genetic \\
\hline Monogenic disorders: \\
Melanocortin-4 receptor mutation \\
Leptin deficiency \\
Proopiomelanocortin deficiency \\
Syndromes \\
Prader-Willi \\
Bardet-Biedl \\
Cohen \\
Alstrom \\
Fröhlich \\
Neurologic \\
Brain injury \\
Brain tumor \\
Consequences of cranial irradiation \\
Hypothalamic obesity \\
Endocrine \\
Hypothyroidism \\
Cushing syndrome \\
Growth hormone deficiency \\
Pseudohypoparathyroidism \\
Psychological \\
Depression \\
Eating disorders \\
Drug-induced \\
Tricyclic antidepressants \\
Oral contraceptives \\
Antipsychotics \\
Anticonvulsants \\
Glucocorticoids \\
\hline
\end{tabular}

Until quite recently, childhood obesity was viewed as a cosmetic problem only. The major risks associated with obesity in children and adolescents were just considered when obesity persisted in the adulthood. Recently, however, a significant increase in the cardiovascular risk associated with obesity in childhood, probably due to obesity-metabolic disarrangement has been observed. Since then, discussion on strategies for treating childhood and adolescent obesity has been promoted worldwide.

Prevention and effective treatment of obese children and adolescents must be a priority. The treatment is based on life style modification, which includes dietary modifications (a balanced healthy diet) and starting or increasing regular physical activity. Short-term pharmacological therapy was found beneficial in obese adolescents, according to some reviews (7). Elaboration of strategies targeting the prevention of excess weight gain might be useful to warrant maintenance of a healthy weight and might begin as soon as in infancy.

\section{DIAGNOSTIC CONSIDERATIONS}

Obesity can be defined as generalized or localized fat mass accumulation as a result of energy disbalance, caused by the interplay of genetic and ambient factors (8). The diagnosis of obesity is fundamentally clinical, based on anthropometric features.

Body mass index $\left[\mathrm{BMI}=\right.$ weight $(\mathrm{kg}) /$ height $\left.(\mathrm{m})^{2}\right]$ is, in adults, the international standard that defines overweight (BMI between 25 and $30 \mathrm{~kg} / \mathrm{m}^{2}$ ) and obesity $\left(B M I \geq 30 \mathrm{~kg} / \mathrm{m}^{2}\right)$. In children and adolescents, nevertheless, a consensus of a BMI cut-off point defining overweight or obesity has not been established yet.

Usually, for clinical practice and epidemiologic studies, child overweight and obesity are assessed by means of indicators based on weight and height measurements, such as weight-for-height measures or BMI (8). Percentiles specific for age and gender define underweight, healthy weight, overweight, and obesity in children (7). The use of 2 cut-off points, namely, BMI at the 95 th percentile and 85 th percentile, captures varied risk levels and minimizes both overdiagnosis and underdiagnosis. When the BMI is $<85$ th percentile, body fat levels are likely to pose little risk. On the other hand, when the BMI is $>95$ th percentile, as body fat levels are higher, there is risk.

A BMI from 85th to 94th percentile represents an increase in the risk of obesity-related disease that var- 
ies according to body composition, "BMI trajectory", family history, and other factors. Recently, it has been suggested that, when the BMI is > 95th percentile, the term "obesity" should replace "overweight" and, when the BMI is from the 85th to 94th percentile, "overweight" should replace "at risk of overweight". For older adolescents, a BMI in the 95th percentile may be higher than a BMI of $30 \mathrm{~kg} / \mathrm{m}^{2}$, the adult obesity cutoff. In this context, it is recommended that obesity in youths must be defined as a BMI at the 95th percentile or a BMI of $30 \mathrm{~kg} / \mathrm{m}^{2}$, whichever is lower (5). Besides, a need for a third cut-off point to define severe obesity in childhood has been discussed, as an adolescent weighing $90 \mathrm{~kg}$ and another weighing $120 \mathrm{~kg}$ are in the same BMI category (> 95th percentile) but markedly face different social and medical effects. Children with extreme obesity are at high risk for multiple cardiovascular disease risk factors (5). In children, the distribution of BMI percentiles varies according to gender and age as in weight and height percentiles (5). There are specific BMI charts for boys and girls, CDC charts are most commonly used (Figures 1 and 2) (9). The International Obesity Task Force (IOTF) has also published a BMI cut-off for overweight and obesity in adolescents based on body mass index from six large nationally representative cross-sectional surveys in Brazil, Great Britain, Hong Kong, the Netherlands, Singapore, and the United States (Table 2). This definition is less arbitrary and more international than others and has been adopted as a reference worldwide. More recently, Conde and Monteiro in Brazil also published a classification chart of BMI in the Brazilian pediatric population based on data from the National research of Nutrition and Health performed in 1989 (Table 3) (11).

The BMI is an important screening tool, but it must be integrated with other information in the health assessment, such as detailed medical history and physical examination, that must include blood pressure measurement (using normative data for blood pressure for children from 6 to 17 years according to age, gender, and height for 50th, 90th, and 95th/97th percentiles) (12). Estimated prevalence of hypertension in childhood can reach values as high as $30 \%$ (13). A correlation between insulin resistance and hypertension has been demonstrated in this group.

Waist circumference (WC), that is measured in the midline between iliac crest and the inferior part of the last rib, is the most simple and representative anthropometric index, that estimates intra-abdominal fat (visceral fat), besides central obesity and cardiometabolic risk. The increase in abdominal fat has been associated in children and adolescents to metabolic syndrome components, namely arterial hypertension, hypertrygliceridemia, low

Table 2. The International Obesity Task Force (IOTF) classification criteria for overweight and obesity in adolescents based on BMl from six large nationally representative cross-sectional surveys in Brazil, Great Britain, Hong Kong, the Netherlands, Singapore, and the United States

\begin{tabular}{|c|c|c|c|c|}
\hline \multirow[t]{2}{*}{ Age (years) } & \multicolumn{4}{|c|}{ BMI (weight (kg)/height (m)²) } \\
\hline & Boys & Girls & Boys & Girls \\
\hline 2 & 18.4 & 18.0 & 20.1 & 20.1 \\
\hline 2.5 & 18.1 & 17.8 & 19.8 & 19.5 \\
\hline 3 & 17.9 & 17.6 & 19.4 & 19.4 \\
\hline 3.5 & 17.7 & 17.4 & 19.4 & 19.2 \\
\hline 4 & 17.6 & 17.3 & 19.3 & 19.1 \\
\hline 4.5 & 17.5 & 17.2 & 19.3 & 19.1 \\
\hline 5 & 17.4 & 17.1 & 19.3 & 19.2 \\
\hline 5.5 & 17.5 & 17.2 & 19.5 & 19.3 \\
\hline 6 & 17.6 & 17.3 & 19.8 & 19.7 \\
\hline 6.5 & 17.7 & 17.5 & 20.2 & 20.1 \\
\hline 7 & 17.9 & 17.8 & 20.6 & 20.5 \\
\hline 7.5 & 18.5 & 18.0 & 21.1 & 21.0 \\
\hline 8 & 18.4 & 18.0 & 21.6 & 21.6 \\
\hline 8.5 & 18.8 & 18.7 & 22.2 & 22.2 \\
\hline 9 & 19.1 & 19.1 & 22.8 & 22.8 \\
\hline 9.5 & 19.5 & 19.5 & 23.4 & 23.5 \\
\hline 10 & 19.8 & 19.9 & 24.0 & 24.1 \\
\hline 10.5 & 20.2 & 20.3 & 24.6 & 24.8 \\
\hline 11 & 20.6 & 20.7 & 25.1 & 25.4 \\
\hline 11.5 & 20.9 & 21.2 & 25.6 & 25.1 \\
\hline 12 & 21.2 & 21.7 & 26.0 & 26.7 \\
\hline 12.5 & 21.6 & 22.1 & 26.4 & 27.2 \\
\hline 13 & 21.9 & 22.6 & 26.8 & 27.8 \\
\hline 13.5 & 22.3 & 23.0 & 27.2 & 28.2 \\
\hline 14 & 22.6 & 23.3 & 27.6 & 28.6 \\
\hline 14.5 & 23.0 & 23.7 & 28.0 & 28.9 \\
\hline 15 & 23.3 & 23.9 & 28.3 & 29.1 \\
\hline 15.5 & 23.6 & 24.2 & 28.6 & 29.3 \\
\hline 16 & 23.9 & 24.4 & 28.9 & 29.4 \\
\hline 16.5 & 24.2 & 24.5 & 29.1 & 29.6 \\
\hline 17 & 24.5 & 24.7 & 29.4 & 29.7 \\
\hline 17.5 & 24.7 & 24.8 & 29.7 & 29.8 \\
\hline 18 & 25 & 25 & 30 & 30 \\
\hline
\end{tabular}




\begin{tabular}{|c|c|c|c|c|c|c|}
\hline \multirow[t]{2}{*}{ Age (months) } & \multicolumn{3}{|c|}{ Male } & \multicolumn{3}{|c|}{ Female } \\
\hline & $\begin{array}{c}{ }^{*} \mathrm{LW} \\
\left(17.5 \mathrm{~kg} / \mathrm{m}^{2}\right)\end{array}$ & $\begin{array}{c}\text { OW } \\
\left(25 \mathrm{~kg} / \mathrm{m}^{2}\right)\end{array}$ & $\begin{array}{c}\text { OB } \\
\left(30 \mathrm{~kg} / \mathrm{m}^{2}\right)\end{array}$ & $\begin{array}{c}{ }^{*} \mathrm{LW} \\
\left(17.5 \mathrm{Kg} / \mathrm{m}^{2}\right)\end{array}$ & $\begin{array}{c}\text { OW } \\
\left(25 \mathrm{~kg} / \mathrm{m}^{2}\right)\end{array}$ & $\begin{array}{c}\text { OB } \\
\left(30 \mathrm{~kg} / \mathrm{m}^{2}\right)\end{array}$ \\
\hline 24.0 & 13.77 & 19.17 & 21.98 & 13.95 & 18.47 & 20.51 \\
\hline 24.5 & 13.77 & 19.13 & 21.94 & 13.94 & 18.43 & 20.47 \\
\hline 30.5 & 13.76 & 18.76 & 21.53 & 13.87 & 18.03 & 20.00 \\
\hline 36.5 & 13.70 & 18.45 & 21.21 & 13.76 & 17.70 & 19.64 \\
\hline 42.5 & 13.61 & 18.20 & 20.98 & 13.66 & 17.44 & 19.38 \\
\hline 48.5 & 13.50 & 18.00 & 20.85 & 13.55 & 17.26 & 19.22 \\
\hline 54.5 & 13.39 & 17.86 & 20.81 & 13.46 & 17.14 & 19.15 \\
\hline 60.5 & 13.28 & 17.77 & 20.85 & 13.37 & 17.07 & 19.16 \\
\hline 66.5 & 13.18 & 17.73 & 20.98 & 13.28 & 17.05 & 19.23 \\
\hline 72.5 & 13.09 & 17.73 & 21.19 & 13.21 & 17.07 & 19.37 \\
\hline 78.5 & 13.02 & 17.78 & 21.48 & 13.15 & 17.12 & 19.56 \\
\hline 84.5 & 12.96 & 17.87 & 21.83 & 13.10 & 17.20 & 19.81 \\
\hline 90.5 & 12.93 & 17.99 & 22.23 & 13.07 & 17.33 & 20.10 \\
\hline 96.5 & 12.91 & 18.16 & 22.69 & 13.07 & 17.49 & 20.44 \\
\hline 102.5 & 12.92 & 18.35 & 23.17 & 13.09 & 17.70 & 20.84 \\
\hline 108.5 & 12.95 & 18.57 & 23.67 & 13.16 & 17.96 & 21.28 \\
\hline 114.5 & 13.01 & 18.82 & 24.17 & 13.26 & 18.27 & 21.78 \\
\hline 120.5 & 13.09 & 19.09 & 24.67 & 13.40 & 18.63 & 22.32 \\
\hline 126.5 & 13.19 & 19.38 & 25.14 & 13.58 & 19.04 & 22.91 \\
\hline 132.5 & 13.32 & 19.68 & 25.58 & 13.81 & 19.51 & 23.54 \\
\hline 138.5 & 13.46 & 20.00 & 25.99 & 14.07 & 20.01 & 24.21 \\
\hline 144.5 & 13.63 & 20.32 & 26.36 & 14.37 & 20.55 & 24.89 \\
\hline 150.5 & 13.82 & 20.65 & 26.69 & 14.69 & 21.12 & 25.57 \\
\hline 156.5 & 14.02 & 20.99 & 26.99 & 15.03 & 21.69 & 26.25 \\
\hline 162.5 & 14.25 & 21.33 & 27.26 & 15.37 & 22.25 & 26.89 \\
\hline 168.5 & 14.49 & 21.66 & 27.51 & 15.72 & 22.79 & 27.50 \\
\hline 174.5 & 14.74 & 22.00 & 27.74 & 16.05 & 23.28 & 28.04 \\
\hline 180.5 & 15.01 & 22.33 & 27.95 & 16.35 & 23.73 & 28.51 \\
\hline 186.5 & 15.29 & 22.65 & 28.15 & 16.63 & 24.11 & 28.90 \\
\hline 192.5 & 15.58 & 22.96 & 28.34 & 16.87 & 24.41 & 29.20 \\
\hline 198.5 & 15.86 & 23.27 & 28.52 & 17.06 & 24.65 & 29.42 \\
\hline 204.5 & 16.15 & 23.56 & 28.71 & 17.22 & 24.81 & 29.56 \\
\hline 210.5 & 16.43 & 23.84 & 28.89 & 17.33 & 24.90 & 29.63 \\
\hline 216.5 & 16.70 & 24.11 & 29.08 & 17.40 & 24.95 & 29.67 \\
\hline 222.5 & 16.95 & 24.36 & 29.28 & 17.45 & 24.96 & 29.70 \\
\hline 228.5 & 17.18 & 24.59 & 29.50 & 17.47 & 24.96 & 29.74 \\
\hline 234.5 & 17.37 & 24.81 & 29.75 & 17.49 & 24.97 & 29.83 \\
\hline 240.0 & 17.50 & 25.00 & 30.00 & 17.50 & 25.00 & 30.00 \\
\hline Z & -2.17 & 1.32 & 2.83 & -1.80 & 1.02 & 2.10 \\
\hline$p$ & 0.015 & 0.907 & 0.998 & 0.036 & 0.847 & 0.982 \\
\hline
\end{tabular}

* $\mathrm{LW}=$ low weight; $\mathrm{OW}=$ overweight; $\mathrm{OB}=$ obesity. 


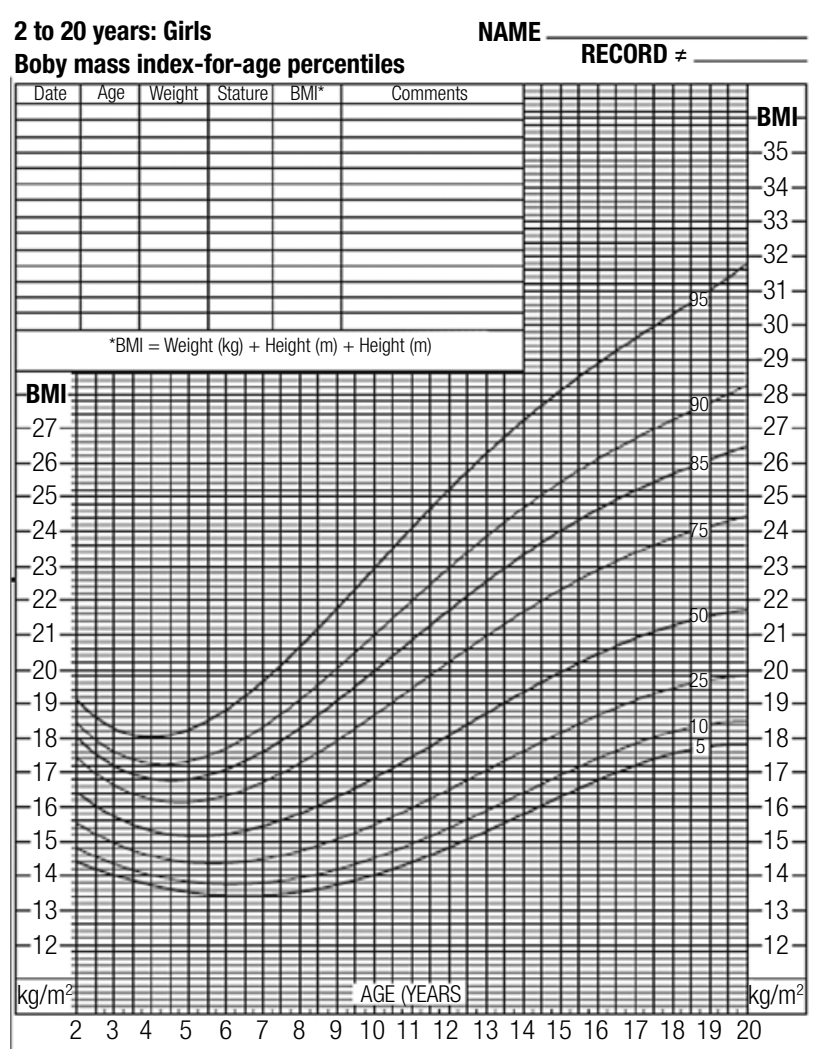

Figure 1. Specific NCHS (CDC) BMl chart for girls.

HDL-c, hyperglycemia, and hyperinsulinemia, with a strong correlation with insulin resistance $(14,15)$. Nevertheless, waist circumference measurements in children and adolescents are not currently recommended. Reference values that identify risk over and above the risk from BMI category are not available. In the future, besides new cut-off points, waist circumference can be a useful clinical tool, providing additional information and influencing the evaluation and treatment of obesity (5).

Physical examination can reveal acanthosis nigricans, a brown to black velvety hyperpigmentation of the skin, usually present in the posterior and lateral folds of the neck, axilla, groins, elbows, and knees that is considered a mark of insulin resistance $(16,17)$. It can be found in up to $90 \%$ of type 2 DM adolescents and also in girls with polycystic ovary syndrome $(13,18)$.

Although less frequent, secondary causes of obesity can be seen in a wide variety of genetic and endocrine disorders (Table 1). Different signs and symptoms can indicate secondary obesity. Hypogonadism, short stature, dysmorphic features, and mental retardation are some examples (6). Children with obesity secondary to genetic or endocrine syndromes typically have characteristic physical examination findings. Children with endogenous obesity are short and often have a delayed or

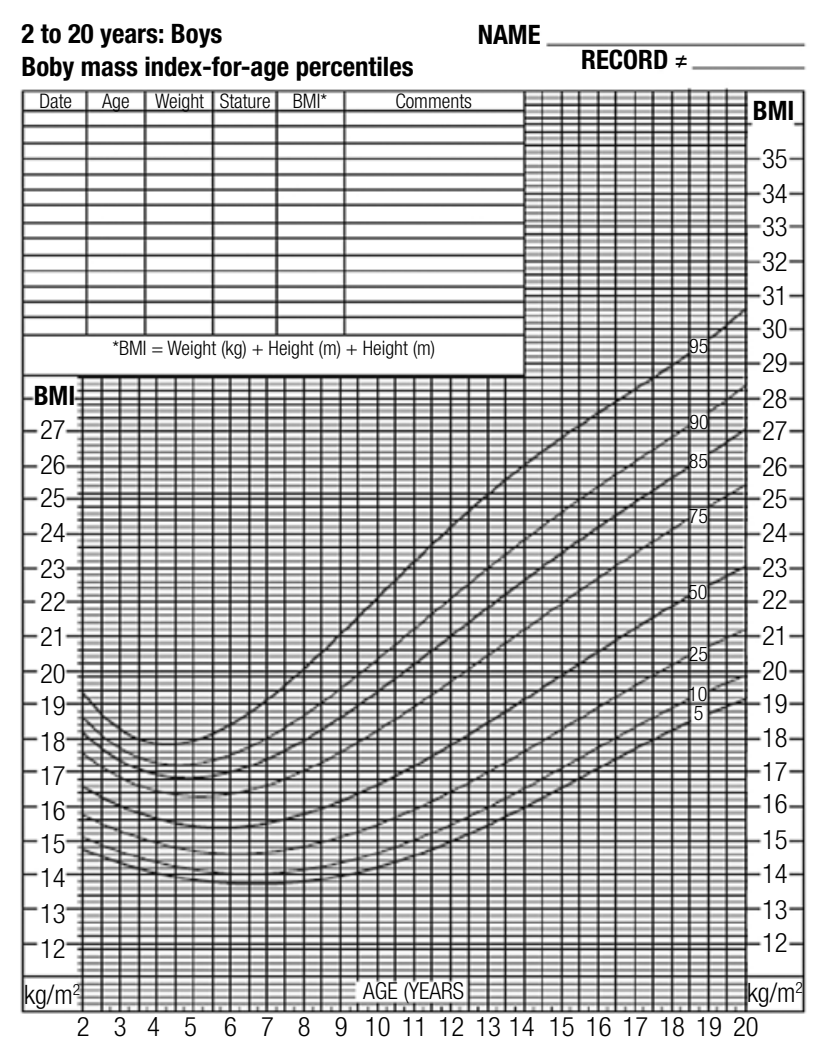

Figure 2. Specific NCHS (CDC) BMI chart for boys.

normal bone age, while children with exogenous obesity are taller and often have growth acceleration along with advance in bone age (6). A careful history and physical examination are usually adequate to rule out or suspect an endogenous cause for obesity in most children.

Laboratory investigation can complement the search for obesity comorbidities in children and adolescents. Disorders in glucose metabolism such as the following can be identified: impaired fasting glucose, impaired glucose tolerance and type 2 diabetes. The most relevant and cost-effective tests are fasting glucose and insulin and 2 hour post-load glucose, following $75 \mathrm{~g}$ of dextrose (19). Basal insulin levels are a clue to insulin resistance, and can be used for homeostatic model assessment (HOMA) index calculation. Dyslipidemia can be assessed to find high triglycerides and low HDL levels, characteristic of the metabolic syndrome.

The evaluation also includes investigation of other obesity-related diseases as they can compromise life expectancy (12). Osteoarticular abnormalities, sleep apnea, non-alcoholic fat liver disease, reproductive tract disorders (like polycystic ovary syndrome), gastroesophagic reflux, and cholelithiasis can be diagnosed based solely on medical history plus physical examination, or with the help of more specific additional exams $(12,20)$. 


\section{TREATING OBESE ADOLESCENTS: GENERAL CONSIDERATIONS}

Excess fat storage arises from an imbalance between energy intake and expenditure. In adolescents, the problem is particularly difficult to treat if overeating is associated with a lack of physical activity, promoted around the world by modern lifestyles (21). Governments, schools, institutions, the media, restaurants and communities can implement environmental strategies to promote the intake of healthy food, limit the access to unneeded food, and encourage healthy physical activity.

Family participation is one of the most important points for treatment success. Several studies of obesity treatment in children have demonstrated the importance of parents' participation in weight control programs (5). Parents and caregivers can serve as role models, authoritative figures, and behaviorists to mold their children's eating and activity habits. Families can learn to eat and exercise healthfully together (21). The greater independence of adolescents means that clinicians should discuss health behaviors directly with them, although clinicians should encourage parents to make the home an environment as healthy as possible (5).

The achievement of permanent healthy lifestyle habits is an excellent goal independent of weight change because of the long-term health benefits of these behaviors. When considering BMI, the goal is the achievement of a percentile under the 85th. Nevertheless, especially before puberty, even a modest weight gain can result in migration to lower BMI percentiles, because of ongoing linear growth. Weight loss is recommended for children older than 7 years with a BMI between the 85th percentile and 95th percentile who have a secondary complication of obesity and for those with a BMI at, or above the 95th percentile (6). Children and adolescents with comorbidities such as non-alcoholic fatty liver disease, idiopathic intracranial hypertension (also known as pseudotumor cerebri), sleep apnea, orthopedic abnormalities, type 2 diabetes mellitus, and arterial hypertension require a faster weight loss, because improvement in medical conditions is also an important sign of long-term health benefits.

During the last decade, several scientific articles have been published about adolescent obese treatment. Studies on lifestyle changes, pharmacologic treatment or surgical interventions have provided important information on strategies for weight loss and maintenance of healthy weight $(22,23)$. However, there is no widely accepted consensus about adolescent obesity treatment, as current recommendations for the clinical management in adolescents are based on the control of weight gain and eventually present comorbidities (24-26).

\section{NON-PHARMACOLOGIC TREATMENT}

When considering non-pharmacological treatment of adolescent obesity, the first goal is to identify the child's dietary and physical activity behaviors that may promote energy imbalance and that are modifiable. The next step is to assess the capacity of the patient and/ or the patient's family to change some or all of these behaviors (5). Targeting realistic behavior changes can help in reaching the treatment objectives.

Sedentary lifestyle begins early in life and worsens throughout childhood and adolescence. Some studies demonstrate that many youth do not achieve the recommended minimum amount of daily physical activity $(27,28)$. The percentage of adolescents participating in daily physical education fell from $41.6 \%$ to $33.0 \%$, between 1991 and 2005. According to the Youth Risk Behavior Surveillance System (YRBSS), only $43.8 \%$ of males and $27.8 \%$ of females were physically active for a total of 60 minutes or more per day on 5 or more of 7 days (29). One study evaluated almost 4500 children aged 9 to 13 years old and found that $61.5 \%$ do not participate in any organized physical activity in their nonschool hours, and $22.6 \%$ do not engage in any leisure-time physical activity (30).

An exercise prescription for health does not need to be complicated. It is consensus that it has to be addressed for age and gender $(27,31)$. It can revolve around activities of daily living. People should choose exercises and activities of their preference. The recommendation for adolescents is the accumulation of at least 30 to 60 minutes of age-appropriate activity on most days of the week (32). Structured physical training is not required for health benefits to occur, and physical activity can be accumulated throughout the day, even through short (10 minutes) bouts of exercise (33). In lifestyle modification, sedentary behaviors such as watching television, playing video games, or using a computer are reduced and more physically active ones encouraged (34).

Schools might be a great vehicle for these lifestyle modifications. In 2006, the American Heart Association (AHA) published a statement on promoting physical activity among children and adolescents focusing on the responsibilities of the school, as summarized on Table 4 (35). 
Table 4. Summary of the policy and practice recommendations endorsed by the AHA statement on promoting physical activity

1. Schools should ensure that all youth participate in a minimum of 30 minutes of moderate to vigorous physical activity during the school day, including active time during physical education classes

2. Schools should deliver evidence based health-related physical education programs that meet national standards at all school levels. These programs should provide substantial amounts of MVPA ( $50 \%$ of class time) and teach students motor and behavioral skills needed to engage in lifelong physical activity

3. States and school districts should ensure physical education is taught by certified and well-qualified teachers

4. States should hold schools accountable for delivering physical education programs that meet national standards for quality and quantity (150 minutes per week in grades $K$ to 8 and 225 minutes per week in grades 9 to 12)

5. Schools should expand physical activity opportunities by providing clubs lessons, intramural sports, and interscholastic sports programs that meet the physical activity needs and interests of students

6. School leaders should promote walking and bicycling to school and work with local governments to ensure that students have safe routes for active transportation

7. Child development centers and elementary schools should provide children with at least 30 minutes of physically active recess during each school day

8. Schools should provide evidence-based health education programs emphasizing behavioral skills focused on increasing physical activity and decreasing sedentary behaviors

9. Colleges and universities should provide professional preparation programs that produce teachers who are highly qualified to deliver evidence-based physical education and health education programs

There is neither sufficient nor definite data supporting diet therapy for losing weight in childhood and adolescence. Diet therapy must focus on caloric ingestion adequacy that is inserted in a well balanced alimentary program that consists of $15 \%$ of total ingested calories from proteins, $50 \%$ to $55 \%$ from carbohydrates, and $30 \%$ from fat. It is sufficient to warrant the correct amount of nutrients for adequate growth and development $(36,37)$. Dietary interventions are aimed at reducing the intake of high-fat foods, simple sugars, and sweetened beverages and at increasing the intake of lower-calorie, high-fiber foods such as fruits, vegetables, and whole grains (6). There are few reports on the use of highly restrictive diets for children or adolescents and long-term outcome data about this strategy has not been reported (5).

\section{PHARMACOLOGIC TREATMENT}

Therapies with pharmacologic agents have been suggested for obese adolescents, since long-term evidence from randomized, controlled trials, showing maintenance of substantial weight loss with lifestyle changes still remains sparse. Consistent data are available with orlistat and sibutramine. Studies with metformin for the treatment of obesity in adolescents have also been done; nevertheless, so far, there is no data to support this indication. Pharmacological treatment has to be considered in case of lack of response to life style modification besides the comorbidities related to obesity.

An Endocrine Society Clinical Practice Guideline based on expert opinion published in 2008 suggests that pharmacotherapy (in combination with lifestyle modification) be considered in: 1) obese children only after failure of a formal program of intensive lifestyle modification; and 2) overweight children only if severe comorbidities persist despite intensive lifestyle modification, particularly in children with a strong family history of type 2 diabetes or premature cardiovascular disease. Pharmacotherapy should be provided only by clinicians who are experienced in the use of antiobesity agents and aware of the potential for adverse reactions (38).

\section{Orlistat}

Orlistat blocks fat absorption in the intestine by inhibiting lipase activity, thereby potentially establishing a negative energy balance (6). The pancreatic lipaseblocker orlistat is approved by the Food and Drug Administration (FDA) for use in adolescents aged 12 to 18 years old with a BMI more than two units above the 95th percentile for the age and gender (39). A one-year study conducted in 539 American adolescents submitted to a hypocaloric diet plus exercise and behavioral therapy that were randomized to orlistat versus placebo has shown a significant decrease in BMI in the orlistat group ( 0.55 versus 0.31 for placebo; $p-0.01)$ when compared with placebo.

The orlistat dosage for adolescents is the same for adults, $120 \mathrm{mg}$ tid. Gastrointestinal adverse effects, such as fatty or oily stools, are common with treatment. Concern regarding possible malabsorption of fat-soluble vitamins and gastrointestinal adverse effects are likely to limit the use of orlistat for the treatment of pediatric obesity $(40,41)$. A daily multivitamin supplement is recommended either 2 hours before or after orlistat is taken, because it may also interfere with the absorption of fat-soluble vitamins (A, D, E, and K) (6).

\section{Sibutramine}

Sibutramine promotes satiety and enhances energy expenditure by inhibiting the reuptake of the neurotransmitters noradrenaline and serotonin (6). In the US, 
sibutramine may be used in adolescents older than 16 years old (5). The addition of sibutramine to a behavior therapy program in a 12 -month placebo-controlled study conducted in obese American adolescents, 12 to 16 years of age, resulted in statistically significant improvements in BMI. At month 12, the estimated mean change in BMI for sibutramine plus behavior therapy was $3.1 \mathrm{~kg} / \mathrm{m}^{2}$ versus $0.3 \mathrm{~kg} / \mathrm{m}^{2}$ for placebo plus behavior therapy $(p-0.001)$; BMI diminished $2.4 \%$ in 7-12 months in the sibutramine group, when compared to placebo (42). Additionally, Berkowitz and colleagues have shown, in a 1 year randomized controlled trial in 498 participants, 12 to 16 years of age (BMI that was at least 2 units more than the US weight mean of the 95th percentile) a reduction in BMI and body weight, and improved metabolic profile in the sibutramine-treated group (43). Our group studied 60 Brazilian adolescents, utilizing sibutramine $10 \mathrm{mg}$ a day, in a 6-month randomized, double-blind, placebo-controlled fashion (44). Patients assigned to the sibutramine group lost an average of $10.3 \pm 6.6 \mathrm{~kg}$ and patients in placebo group lost $2.4 \pm 2.5 \mathrm{~kg}$ ( $\mathrm{p}<0.001$ for difference between groups). Moreover, more than five times as many adolescents assigned to the sibutramine group ( $\mathrm{n}=14 ; 46.6 \%)$ reduced their initial body weight by at least $10 \%$ in comparison to the placebo group ( $\mathrm{p}<$ $0.001)$. Approximately $25 \%$ of adolescents assigned to the sibutramine group $(\mathrm{n}=7)$ reduced their initial weight by at least $15 \%$ in comparison to $0 \%$ in the placebo group $(\mathrm{p}<0.001)(44)$.

The most common adverse effects found in the aforementioned studies, with adolescents taking sibutramine, was tachycardia, that was not a reason to withdraw from treatment (42-44). The maximum mean difference in pulse rate $(3.7$ beats $/ \mathrm{min})$ found in one of the studies conducted in the US, occurred at month 2 (43). Sibutramine labeling instructions for adults recommend that all patients with sibutramine ongoing treatment should be monitored for blood pressure and pulse rate. It is important to notice that pulse rate varies throughout childhood and adolescence, but persistent tachycardia (defined by a rate $\geq 120$ beats $/ \mathrm{min}$ in older children) should be evaluated in standard medical care. Sibutramine effects in heart rate and blood pressure in obese adolescents are generally neutralized by the effective reduction in BMI that seems to be even better than that observed in adults (45). Less frequent observed adverse effects were: headache, dry mouth, constipation, dizziness, insomnia and elevation of blood pressure $(43,44)$.

\section{Metformin}

Metformin is an insulin sensitizer formally indicated for treating insulin resistance in type 1 and type 2 diabetes and polycystic ovary syndrome. It is approved for use in children older than 10 years old. There is a lack of evidence to support metformin for treating obesity in adolescents. A recent study, however, showed significantly more improvement in body composition (weight, BMI, waist circumference) and fasting insulin levels in a small number of obese insulin-resistant pediatric patients with metformin therapy versus placebo (46). In a recent meta-analysis of Randomized Trials for obese adolescent treatment, three randomized trials of metformin monotherapy on hyperinsulinemic, nondiabetic, obese adolescents showed a small non-significant change in obesity outcome at 6 months (7).

\section{BARIATRIC SURGERY IN ADOLESCENTS}

According to the 1991 National Institute of Health Consensus Panel guideline for adults, bariatric surgery is an appropriate treatment modality for adults who have failed conventional weight management efforts when the BMI reaches $40 \mathrm{~kg} / \mathrm{m}^{2}$ or if BMI is $35 \mathrm{~kg} /$ $\mathrm{m}^{2}$ or greater in the presence of significant associated comorbidities. In contrast to numerous published reports investigating the outcome of bariatric surgery in adults, there is a relative paucity of published data on the application of bariatric surgery in adolescents.

Bariatric surgery is being increasingly considered as an adjunct treatment tool, although not a cure for obesity, it can be a helpful for selected, extremely obese adolescents to achieve significant weight loss and improve comorbidities, when used in conjunction with preoperative and postoperative behavioral and dietary intervention (22). This treatment generally leads to substantial weight loss and improvement in medical conditions. However, peri-operative risks, post procedure nutritional risks, and the necessity of lifelong commitment to altered eating make this approach unattractive or inappropriate for many patients (5). In 2004, the American Pediatric Surgical Association and the American Society for Bariatric Surgery established a protocol for the indication of bariatric surgery for particular population (Table 5) $(5,22,47)$.

The Endocrine Society Clinical Practice Guideline based on expert opinion published in 2008 suggests bariatric surgery for adolescents with BMI above $50 \mathrm{~kg} /$ $\mathrm{m}^{2}$, or BMI above $40 \mathrm{~kg} / \mathrm{m}^{2}$ with severe comorbidities, 
Table 5. Criteria for recommendation of bariatric surgery in adolescence

\section{Surgery may be recommended if the conditions mentioned below are} found

- Failure in clinical treatment with multidisciplinary and adequate therapy

- Tanner stage $\geq$ IV

- $\mathrm{BMI}>40 \mathrm{~kg} / \mathrm{m}^{2}$ associated with comorbidities (i.e.: type 2 diabetes, hypertension, dyslipidemia) or BMI $\geq 50 \mathrm{~kg} / \mathrm{m}^{2}$ without comorbidities

- Good comprehension and mental capacity to follow all the necessary procedures before and after surgery

- Do not become pregnant in the year before surgery

- Family support

\section{Surgery must not be indicated}

- If the cause of obesity was corrected by lifestyle/medication

- If the patient has been addicted to drugs in the last year

- If there is any medical, cognitive or psychiatric condition that will make the adherence to treatment difficult or impossible

- Gestation, lactation or the will to be pregnant in the first year of postoperatory.

- Incapacity of procedure comprehension as its consequences by the patient or the parents. That includes the necessity of vitamin supplementation and strict diet from this point in time on

in whom lifestyle modifications and/or pharmacotherapy have failed. Candidates for surgery and their families must be psychologically stable and capable of adhering to lifestyle modifications. Access to experienced surgeons and sophisticated multidisciplinary teams who assess the benefits and risks of surgery is obligatory (38).

Patients should undergo a comprehensive pre- and post-operative evaluation, and have an expert surgeon plus multi-disciplinary support, for optimum outcome. It is very important to exclude secondary causes of obesity and perform a psychiatric and psychological evaluation before surgery $(22,47)$. In the same way, it is interesting to achieve some weight loss before surgery. In several countries, the most popular surgery in adults and adolescents is a restrictive-disabsortive procedure consisting of a gastric reduction and Roux-en- $\Upsilon$ bypass. Laparoscopic surgery has been widely disseminated because of its lower risk of complications when compared to conventional surgery $(22,47,48)$.

Bariatric surgery is a promising, although still controversial, weight loss tool for selected extremely obese adolescents who have failed conventional medical and behavioral therapy for obesity. Early reports of bariatric surgery in adolescents have shown success with this procedure, despite a much higher mean BMI than in adult candidates. Long-term studies are necessary to allow quantitative meta-analysis. Rates of morbidity and mortality after bariatric surgery and resolution of preoperative comorbidities need to be rigorously and prospectively studied.

\section{CONCLUSION}

The nearly 3 -fold increase in youth overweight and obesity during the last decades represents a potentially devastating problem for world health (27). The consequences of this epidemic are costly in economic terms, additionally to physical and emotional suffering. However, numerous studies, position statements, and guidelines have been published in the past 10 to 15 years, suggesting lifestyle, pharmacologic and surgical interventions for this problem. The government, healthcare system, school system, food and entertainment industries, public health professionals, communities and families, all have their responsibility in preventing obesity. Further research is needed to develop interventions for the prevention and treatment of childhood and adolescent obesity.

Disclosure: Amélio F. de Godoy-Matos is a lectures- for Abbott, Glaxo-Smith-Kline and Sanofi-Aventis.

Erika Paniago Guedes is a speaker: Abbott, AstraZeneca, Novo Nordisk, Libbs, Torrent.

No other potential conflict of interest relevant to this article was reported.

\section{REFERENCES}

1. NHANES 2003-2004. Prevalence of overweight and obesity among children and adolescents: United States, 2003-2004.

2. Kelishadi R. Childhood overweight, obesity, and the metabolic syndrome in developing countries. Epidemiol Rev. Advance Access published May 3, 2007:1-15.

3. Wang Y, Monteiro C, Popkin BM. Trends of obesity and underweight in older children and adolescents in United States, Brazil, China and Russia. Am J Clin Nutr. 2002;75:971-77.

4. Pesquisa de Orçamentos Familiares (POF). IBGE, realized between July 2002 and June 2003. www.ibge.gov.br/home/presidencia/ noticias/noticia_impressao.php?id_noticia $=625$.

5. Barlow SE. Expert Committee andTreatment of Child and Adolescent Overweight and Obesity: Expert Committee Recommendations Regarding the Prevention, Assessment, Report Pediatrics. 2007;120;S164-92.

6. Singhal V, Schwenk WF, Kumar S. Evaluation and Management of Childhood and Adolescent Obesity. Mayo Clin Proc. 2007;82(10):1258-64.

7. McGovern L, Johnson JN, Paulo R, Hettinger A, Singhal V, Kamath $\mathrm{C}$, et al. Treatment of pediatric obesity: a systematic review and meta-analysis of randomized trials. J Clin Endocrinol Metab. 2008;93:4600-5.

8. World Health Organization. Physical status: the use and interpretation of anthropometry. Report of a WHO Expert Committee. (WHO Technical Report Series no. 854). Geneva Switzerland: World Health Organization, 1995.

9. Kuczmarski RJ, Ogden CL, Guo SS, Grummer-Strawn LM, Flegal KM, Mei R, et al. 2000 CDC growth charts for the United States: methods and development. Vital Health Stat. 2002;246:1-190.

10. ColeTJ, Bellizzi MC, Flegal KM, Dietz WH. Establishing a standard definition for child overweight and obesity worldwide: international survey. BMJ. 2000;320:1240-3. 
11. Conde WL, Monteiro CA. Body mass index cut-off for evaluation of nutritional status in Brazilian children and adolescents. J Pediatr. 2006;82 (4):267-72.

12. Peeters A, Barendregt JJ, Willekens F, Mackenbach JP, AI Mamun A, Bonneux L. NEDCOM, the Netherlands Epidemiology and Demography Compression of Morbidity Research Group. Obesity in adulthood and its consequences for life expectancy: a life-table analysis. Ann Intern Med. 2003;138:24-32.

13. Ferrannini E, Buzzigoli G, Bonadonna R, Giorico MA, Oleggini M, Graziadei $L$, et al. Insulin resistance in essential hypertension. NEJM. 1987;317(6):350-7.

14. Goran MI, Gower BA. Relation between visceral fat and disease risk in children and adolescents. Am J Clin Nutr. 1999;70:149S-56S.

15. Cook S, Weitzman M, Auinger P, Nguyen M, DietzWH. Prevalence of a metabolic syndrome phenotype in adolescents. Arch Pediatr Adolesc Med. 2003;157:821-7.

16. Goran MI, Ball GDC, Cruz ML. Obesity and risk of type 2 diabetes and cardiovascular disease in children and adolescents. J Clin Endocrinol Metab. 2003;88(4):1417-27.

17. American Diabetes Association. Type 2 diabetes in children and adolescent. Pediatrics. 2000;05:671-80.

18. Legro RS. Detection of insulin resistance and its treatment in adolescents with polycystic ovary syndrome. J Pediatr Endocrinol Metab. 2002;15(Suppl 15);1367-68.

19. Weiss $R$, Caprio $S$. The metabolic consequences of childhood obesity. Best Pract Res Clin Endocrinol Metab. 2005;19(3):405-19.

20. Must A, Jacques PF, Dallal GE, Bajema CJ, Dietz WH. Long-term morbidity and mortality of overweight adolescents. A followup of the Harvard Growth Study of 1922 to 1935 . N Engl J Med. 1992;327:1350-5.

21. Society for Adolescent Medicine. Preventing and treating adolescent obesity: A position paper of the Society for Adolescent Medicine. J Adolesc Health. 2006;38:784-7.

22. Xanthakos SA, Daniels SR, Inge TH. Bariatric surgery in adolescents: an update. Adolesc Med Clin. 2006;17(3):589-612.

23. Cook S, Weitzman M, Auinger P, Barlow SE. Screening and counseling associated with obesity diagnosis in a national survey of ambulatory pediatric visits. Pediatrics. 2005;116(1):112-6.

24. Lobstein T, Baur L, Uauy R; IASO International Obesity Task Force. Obesity in children and young people: a crisis in public health. Obes Rev. 2004;5:4-104.

25. Cook S, Gidding SS. Modifying cardiovascular risk in adolescent obesity. Circulation. 2007;115(17):2251-3.

26. Ford ES, Li C, Cook S, Choi HK. Serum concentrations of uric acid and the metabolic syndrome among US children and adolescents. Circulation. 2007;115(19):2526-32.

27. La Fontaine T. Physical activity: the epidemic of obesity and overweight among youth: trends, consequences, and interventions. Am J Lifestyle Med. 2008;2:30-6.

28. Kimm SY, Glynn NW, Kriska AM, Barton BA, Kronsberg SS, Daniels $S R$ et al. Decline in physical activity in black girls and white girls during adolescence. N Engl J Med. 2002;347:709-15.

29. Centers for Disease Control and Prevention. Youth Risk Behavior Surveillance System. Available at: http://www.cdc.gov/HealthyYouth/yrbs/index.htm. Accessed September 7, 2007.

30. Duke J, Huhman M, Heitzler C. Physical activity levels among children aged $9-13$ years in the United States, 2002. Morb Mortal Wkly Rep. 2003;290:1308-9.

31. Ogden CL, Flegal KM, Carrol MD, Johnson CL. Prevalence and trends in overweight among US children and adolescents, 19992000. JAMA. 2002;288:1728-32.
32. Kavey RE, Daniels SR, Lauer RM, Atkins DL, Hayman LL, Taubert $\mathrm{K}$, et al. American Heart Association. American Heart Association guidelines for primary prevention of atherosclerotic cardiovascular disease beginning in childhood. J Pediatr. 2003;142(4):368-72.

33. Grief SN, Talamayan KS. Preventing obesity in the primary care setting. Published on primarycare.theclinics.com 625-43, 2008.

34. Andersen RE, Crespo CJ, Bartlett SJ, Cheskin LJ, Pratt M. Relationship of physical activity and television watching with body weight and level of fatness among children: results from theThird National Health and Nutrition Examination Survey. JAMA. 1998;279(12):938-42.

35. Pate RR, Davis MG, Robinson TN. Promoting physical activity in children and youth: a leadership role for schools. Circulation. 2006;114:1214-24.

36. Patrick K, Norman GJ, Calfas KJ, Sallis JF, Zabinski MF, Rupp J, et al. Diet, physical activity, and sedentary behaviors as risk factors for overweight in adolescence. Arch Pediatr Adolesc Med. 2004;158(4):385-90.

37. Obarzanek E, Kimm SY, Barton BA, Van Horn LL, Kwiterovich Jr. PO, Simons-Morton DG, et al. Long-term safety and efficacy of a cholesterol-lowering diet in children with elevated low-density lipoprotein cholesterol: seven-year results of the Dietary Intervention Study in Children (DISC). Pediatrics. 2001;107:256-64.

38. August GP, Caprio S, Fennoy I, Freemark M, Kaufman FR, Lustig $\mathrm{RH}$, et al. Prevention and treatment of pediatric obesity: an endocrine society clinical practice guideline based on expert opinion. J Clin Endocrinol Metab. 2008;93(12):4576-99.

39. Chanoine JP, Hampl S, Jensen C. Effect of orlistat on weight and body composition in obese adolescent: a randomized controlled trial. JAMA. 2005;293:2873-83.

40. Maahs D, de Serna DG, Kolotkin RL, Ralston S, Sandate J, Qualls C et al. Randomized, double-blind, placebo-controlled trial of orlistat for weight loss in adolescents. Endocr Pract. 2006;12(1):18-28.

41. McDuffie JR, Calis KA, Booth SL, Uwaifo GI, Yanovski JA. Effects of orlistat on fat-soluble vitamins in obese adolescents. Pharmacotherapy. 2002;22(7):814-22.

42. Berkowitz RI, Wadden TA, Tershakovec AM, Cronquist JL. Behavior therapy and sibutramine for the treatment of adolescent obesity: a randomized controlled trial. JAMA. 2003;289:1805-12.

43. Berkowitz RI, Fujioka K, Daniels SR, Hoppin AG, Owen S, Perry AC, S, et al; Sibutramine Adolescent Study Group. Effects of Sibutramine Treatment in Obese Adolescents. Ann Int Med. 2006;145(2):81-90.

44. Godoy-Matos A, Carraro L, Vieira A, Oliveira J, Guedes EP, Mattos $L$, et al. Treatment of obese adolescents with sibutramine: a randomized, double, controlled study. J Clin Endocrinol Metab. 2005;90(3):1460-5.

45. Daniels SR, Long B, Crow S, Styne D, Sothern M, Vargas-Rodriguez I, et al; for the Sibutramine Adolescent Study Group. Cardiovascular effects of sibutramine in the treatment of obese adolescents: results of a randomized, double-blind, placebo-controlled study. Pediatrics. 2007;18:147-57.

46. Srinivasan S, Ambler GR, Baur LA, Garnett SP, Tepsa M, Yap F, et al. Randomized, controlled trial of metformin for obesity and insulin resistance in children and adolescents: improvement in body composition and fasting insulin. J Clin Endocrinol Metab. 2006;91(6):2074-80.

47. IngeTH, Krebs NF, Garcia VF, Skelton JA, Guice KS, Strauss RS, et al. Bariatric surgery for severely overweight adolescents: concerns and recommendations. Pediatrics. 2004;114(1):217-23. Review.

48. Apovian CM, Baker C, Ludwig DS, Hoppin AG, Hsu G, Lenders C, et al. Best practice guidelines in pediatric/adolescent weight loss surgery. Obes Res. 2005;13(2):274-82. Review. 